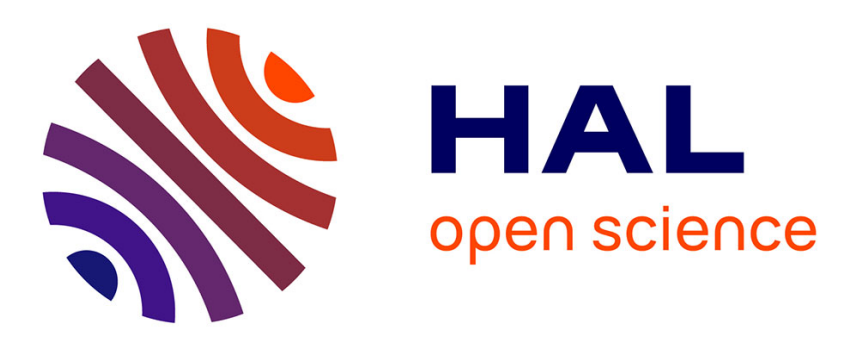

\title{
Integration of new electronic payment systems into B2C internet commerce
}

\author{
Refka Abdellaoui, Marc Pasquet, Olivier Berthelier
}

\section{To cite this version:}

Refka Abdellaoui, Marc Pasquet, Olivier Berthelier. Integration of new electronic payment systems into B2C internet commerce. The International Symposium on Collaborative Technologies and Systems (CTS), 2011, Philadelphie, United States. 8 p. hal-01002467

\section{HAL Id: hal-01002467 \\ https://hal.science/hal-01002467}

Submitted on 6 Jun 2014

HAL is a multi-disciplinary open access archive for the deposit and dissemination of scientific research documents, whether they are published or not. The documents may come from teaching and research institutions in France or abroad, or from public or private research centers.
L'archive ouverte pluridisciplinaire HAL, est destinée au dépôt et à la diffusion de documents scientifiques de niveau recherche, publiés ou non, émanant des établissements d'enseignement et de recherche français ou étrangers, des laboratoires publics ou privés. 


\title{
Integration of New Electronic Payment Systems into B2C Internet Commerce
}

\author{
Refka Abdellaoui, Marc Pasquet, Olivier Berthelier \\ Laboratoire GREYC: ENSICAEN - University of Caen - CNRS \\ refka.abdellaoui@greyc.ensicaen.fr - marc.pasquet@ensicaen.fr-olivier.berthelier@limonetik.com
}

\begin{abstract}
E-commerce has witnessed a considerable growth during last years which has created new financial needs and new payment scenarios. But despite this growth, not all payment instruments are online yet and bank payment card (credit cards, smart cards) still the primary mean of online payment today. Obviously, this is related to many payment system integration problems therefore merchants can not accept easily a new payment instrument instead of the bank card. In this paper we propose a new way to integrate a payment system that resolves many integration issues while guaranteeing payment system requirements.
\end{abstract}

Index Terms-Electronic Commerce, Internet Payment, Payment Service Provider, Payment Security, Integration, Non Bank Payment Card.

\section{INTRODUCTION}

The growth of e-commerce has created new financial needs and payment means. The focus of this paper is on the integration of payment systems into B2C Internet commerce. Our major motivation for this study starts from the observation that not all payment instruments are online yet despite the growth of electronic commerce. Therefore, the main goals of our research activity are to study integration system payment problems and to propose a new payment model in order to design an easier way to integrate new payment instruments.

We will start with studding the importance of the payment in the online transaction process, then we will analyse different factors related to the integration of payment systems into B2C e-commerce in order to propose in section III a new model that resolves different integration issues.

\section{Payment as a Central Part of E-Commerce}

Electronic commerce can be defined as the process of advertisement, sale, insurance and payment of products or services over computer networks. The fast spread of the internet has made electronic commerce a new and high effective tool for performing business transactions. Online transaction process and phases of payment mechanisms are examined within the present section.

\section{A. Online Transaction Process}

The complexity of e-commerce transactions has been growing rapidly in the last few years. Therefore, different payment systems have appeared one after one. There are different ways to model a complete transaction process for e-commerce and to split it into steps for analytical purposes. The Electronic Payment Systems Observatory (ePSO) presents one way [1] summarized in figure 1 that models the on-line e-commerce transaction process with input and output states which consist on the Buyer (B) and the Client (C) who exchange a specified value against specified goods/services and an intermediary financial institution $(F)$ that guaranties the exchange of monetary value.

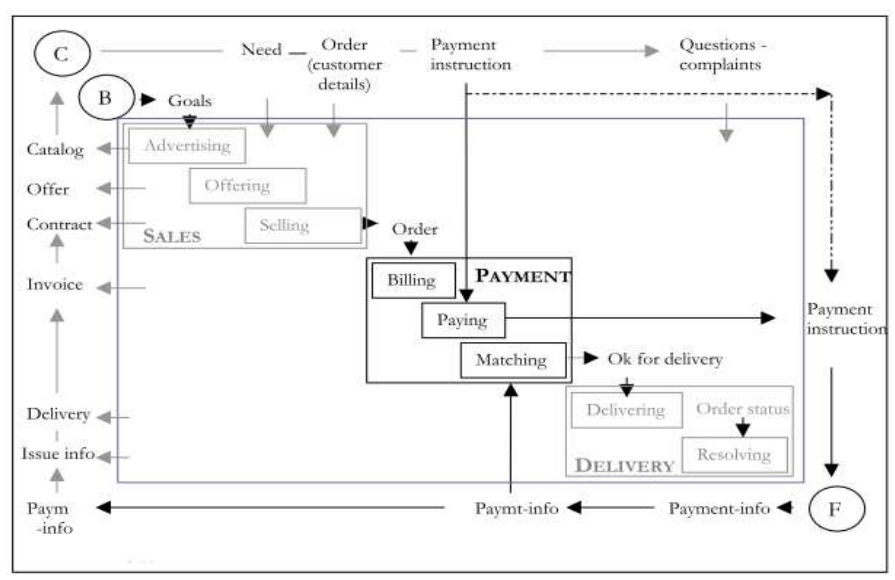

Figure 1. Online Transaction Process

As it is presented in figure 1, ePSO distinguishes three main functions during the online transaction process: sales, payment and delivery. The sales phase, consists on communicating products and services (advertising), offering different goods and services and selling them in internet. The delivery phase contains the delivery of goods/services and the resolving of eventual delivery or payment issues related to the purchase. The payment phase is viewed as a central part of an on-line transaction. During this phase, the merchant produces the invoice (billing), the buyer pays the seller by giving a payment instruction (paying) and the seller matches the payment result with the orders and feeds the result into the back-office. Choice of payment methods, as well as clearing and settlement, belong to the major part of this phase.

\section{B. Internet Payment Process}

As payment is an integral part of the online transaction process [2], electronic payment system is an integral part of ecommerce. Therefore in this paper we will focus on the studding of internet payment process.

The ePSO splits internet payment process into three subfunctions; billing, paying and matching and since the purpose of this paper is to discuss internet payment system integration, we propose a new division of the transaction payment phase which is, in our point of view, more adequate with the aim of our research study. We assure that the internet payment process can be split 
into three subfunctions: Front-End, Payment, Back-End.

\section{B.1 Front-End}

In $\mathrm{B} 2 \mathrm{C}$ e-commerce, the e-shop is central for the merchant. Usually the seller presents a catalogue of products and services and chooses a sales mechanism. The importance of the design of the merchant website is often dealt with the context of the client experience and ergonomic design to prevent the risk of shopping cart abandonment. It is important to display clearly different accepted payment means and order information (amount, basket,...).

\section{B.2 Payment}

After choosing the payment mean, the client is redirected to the payment page where s/he gives her/his payment card credentials. As many researches indicate that trust plays an important role in helping users overcome perceptions of risk and uncertainty in the use and acceptance of new technology [3], the merchant must secure the payment page and reduce fraud risks, in particular he must protect client payment information. During this step, the payment system performs the necessary communications with financial institutions/banks in order to get the payment authorization and guaranty the payment. If the client chooses to pay with many payment means, the payment system must also be able to perform payment orchestration.

\section{B.3 Back-End}

The online transaction process does not stop in electronic payment, there still many operations to perform after the payment, those operations are typically accessible through a Back End that permits the matching between payments and orders (charge, authorization cancellation, refund,...). This step becomes more complicated when the transaction payment is done with many payment methods, because payment instructions differ according to the payment mean [4]; pay-now, pay-later or pay-before.

After presenting the importance of the payment process on the e-commerce transaction and describing different payment phases, we propose to study different related factors to the integration of a new payment system.

\section{INTERNET PAYMENT RELATED FACTORS}

Our understanding of the payment integration problem starts from the observation that not all payment instruments are online yet. In order to analyse this situation, we propose to study different related factors to the designing of a payment system for B2C commerce.

\section{A. Variety of Payment Means}

Electronic payment systems have been in operations since 1960 and have been expanding rapidly as well as growing in complexity. The Electronic Payment Systems Observatory (ePSO) lists about 80 schemes B2C payment methods. Of course, status of different payment instrument and states of deployment vary considerably and as we will detail further below, the importance and acceptance of these payment schemes also vary according to customer use of those payment instrument.
In this section, we propose a classification of different electronic payment systems as a tool that will help us to compare different integration ways in electronic commerce scheme. We assume that the electronic payment system can be broadly divided into two general types; bank card payment systems and non bank card payment systems.

\section{A.1 Bank Card Payment Systems}

Bank cards include all different online cards issued by banks such as credit card, smart card, debit card, etc. This type of payment system is widely accepted by consumers and merchants throughout the world, and considered as the most popular methods of payments for goods and services purchased online [5]. Bank card system consists of Cardholders (consumers), Merchants (sellers), Card Issuing Banks (Issuer), Acquiring Banks (Acquirer) and Credit Card Associations.

In bank card scheme, the Issuer maintains the account of the cardholder and gives him/her a card for payment and bears the risk of fraudulent use of this card. On the other hand, the merchant is in agreement with an acquirer in order to receive payments on his behalf. Banks are organized in Credit Card Associations (such as Visa or MasterCard) that set the transaction rules between Issuer and Acquirer.

\section{A.2 NonBank Card Payment Systems}

Since the beginning of e-commerce, some consumers do not want to be unwilling to use their credit cards on the Internet therefore new digital money schemes has been needed and many payment instrument appear.

We assume that NonBank cards are all other payment instruments alternative to bank payment cards on internet like eloyalty cards, rewards cards, paypal, etc. Generally a non bank card system involves three entities; the client, the merchant and the financial institution that issues payment cards. In this system, the same company contracts with customers as well as merchants and operates the network interfaces directly with merchants and consumers, in addition to processing transactions, issuing cards and managing the payment network.

\section{A.3 Comparison}

Bank cards are the primary means of payment for goods and services purchased online. In terms of transactions, the ACSEL (french association of online service providers and merchants) reports that in 2009, 85\% of Internet purchases are made using the CB (Carte Bancaire) card. According to the TNS Sofres survey and Gartner Data, the credit card is the most widely used means of payment on the Internet in Europe and US. Bank cards are undeniably the most appropriate means since they are both fast and flexible. In another hand, there is no yet a real demand for others payment mean like prepaid card (gift card, loyalty card,...) as an Internet payment option.

Although the increase of online bank card fraud on internet [6], bank cards still the most profitable system for the merchant. In fact, there are several issues associated with online bank card use. Chief among them is fraud, which is perpetrated by both cardholders and merchants. Another problem is the lack of security that can lead to the compromise of card numbers stored in online databases. Bank card system security on internet is 
especially based on the use of the Secure Sockets Layers (SSL) protocol, which is not enough. Therefore, many new standards have been invented like 3D-secure that has as purpose to authenticate the cardholder securely, but the use of this new protocol has altered the client experience during the e-commerce transaction. Many merchants, like "Pecheur.com", have estimated the diminution of their turnover after the integration of 3D-secure between $15 \%$ and $20 \%$, a proportion noted in many e-market where 3D-secure where installed [7]. Which leads us to the conclusion that the widespread use of bank card on internet is not because the bank card system is the most secure system but because the bank card is the most payment mean hold by consumers, so it seems natural that clients use this mean of payment on internet.

\section{B. Electronic Payment Requirements}

We propose to study in this section another factor which can influence the integration of payment system into online shop. An electronic payment system must guaranty some requirements assessed along the following four dimensions [8] summarized in table 1 .

\begin{tabular}{|l|l|}
\cline { 2 - 2 } \multicolumn{1}{c|}{} & \multicolumn{1}{c|}{ Description } \\
Technological & - Authentication \\
Requirements & - Integrity \\
& - Confidentiality \\
& - Non Repudiation \\
\hline \multirow{4}{*}{ Economic } & - The cost of Transaction \\
Requirements & - Atomic exchange \\
& - User Range (System accessibility) \\
& - Value Mobility (value is used anywhere) \\
\hline \multirow{2}{*}{ Social } & - Return On Investment (ROI) \\
Requirements & - Privacy \\
& - Accessibility \\
& - Mobility \\
\hline \multirow{5}{*}{ Legal } & - Digital Signature \\
Requirements & - Digital Transfer \\
& - Legality of Payment \\
& - E-commerce Contracts \\
& - Technical Standards \\
& - Rental Taxes \\
& - International Transactions \\
& - Intellectual Property Protection \\
\hline
\end{tabular}

Table 1. E-Payment System Requirements

\section{B.1 Technological Requirements}

When designing an electronic payment system, the system's ability to guaranty the effectiveness and the security of each transaction and the degree of compatibility with the online shop must be taken into consideration [9]. A payment system requires the greatest level of security in electronic commerce transactions [10]. For this reason, it must guaranty at least confidentiality, authenticity, integrity and non-repudiation of transactions.

\section{B.2 Economic Requirements}

Economic requirements deal with the cost of transaction which refers to the amount paid by the client and the merchant involved in this transaction for example in choosing the electronic payment system for small payments, the cost of the transaction might be a deciding factor. Economic assessments include also atomic exchange which means that the consumer will pay money or something equivalent in value. An electronic payment system must also be accessible in all countries of the world, to all ages (user range). A payment method must be not restricted to the company that created the value which can be used in different countries or exchanged for currency in equal value. Economic needs deal also with financial risks [11], because consumers and merchants are very concerned about the degree of security involved in online transactions. So, in addition to security measures guaranteed by technological aspects, a payment system must anticipate the case when consumer card information are stolen or when a financial partner goes bankrupt. An important economic assessment is the Return On Investment(ROI) which is a performance measure used to evaluate the efficiency of an investment. Thus, the question of what will happen if the merchant spends much money to integrate/accept the payment method and there is no one who uses this payment mean, should be considered when designing the electronic payment system.

\section{B.3 Social Requirements}

In addition to satisfying the technical and economic needs, the electronic payment system still needs to address the social needs while society has to trust and use it. Payment system must prevent companies or financial institutions from tracing user information and must be simple and user-friendly. As social needs, electronic payment methods should also be accessible anywhere. This is another factor that will affect a user's decision when selecting a payment system.

\section{B.4 Legal Requirements}

Electronic payment system must abide by governmental regulations and the law and guaranty all necessary proofs (digital signature, contracts,...) to protect users performing domestic/ international transactions.

\section{Typology of Payment Systems}

In order to determine how to design the payment system, it is important to understand different typologies of payment schemes. On Internet, there are two types of payment systems; traditional payment systems and payment systems with an intermediary party.

\section{C.1 Traditional Payment Systems}

In the traditional payment systems, the merchant has to integrate shopping software in the data processing environment and add payment functions into the online-shop to get payments. In this case the payment mean is displayed directly in the merchant website and the payment is processed by the merchant server. So to be available in Internet, payment means must be integrated directly on different e-markets which may take much time because electronic markets are different from each other.

Merchant that performs this type of payment system must guaranty a high level of security and be able to manage fraud risks and guaranty technological requirements presented in the 
previous section. Therefore, the merchant has to perform many technical mechanisms to secure and maintain the payment system.

When the payment system is directly integrated into the online shop, the merchant is the only responsible of the payment security, therefore, the merchant server must be compliant to the Payment Card Industry Data (PCI) Security Standard (DSS) which is a worldwide information security standard defined by the Payment Card Industry Security Standards Council. This standard was created to help payment card industry organizations that process card payments to prevent credit card frauds by increasing controls around payment data and its exposure to compromise. But in order to obtain the compliance certificate, the merchant payment system must guaranty a high level of security which may be expensive in term of time and cost because e-payment systems are complex, expensive and need high skilled people for operating.

\section{C.2 Payment Systems with an Intermediary Entity}

As an alternative to the traditional payment system, generally, the merchant outsources payment functions to a bank or a Payment Service Provider (PSP) that processes cardholder information and payment authorization request and guaranties the security of payment. Typically, a PSP can connect the merchant to multiple acquiring/issuing banks and card schemes, thereby making the merchant less dependent on financial institutions. Furthermore, a PSP can offer reconciliation services, risk management and multi-currency functionality. This solution is not simple as it seems to be because the merchant must although open a bank account in order to receive and process payments and connect his website to a payment gateway and must be able to redirect securely the customer to the payment page of the PSP. Therefore, and as we presented in a previous research paper [12], the merchant must install an application on his server to perform various cryptographic operations and to secure the redirection of the client to the PSP payment page.

PSPs help merchants to accept many payment methods which include bank payment cards as well as non bank payment cards. They can also connect the merchant sever to several acquiring banks and payment networks and be in charge of such technical connections with external network. This releases the merchant from establishing such connections especially when operating internationally.

This leads us to the conclusion that outsourcing payment services makes payment system integration easier, but after displaying the payment mean and connecting to a payment gateway, the merchant still needs to resolve back end issues and especially how to match orders and payments and to manage financial operations (charge, chargeback,...) during the transaction process and fund transfer.

In practice PSPs develop customer specific interfaces to facilitate the matching function or offer matching services in the back-office, but they do not manage financial flows, they only propose a technical solution that connects securely the merchant to the acquirer and then forwards the payment authorization response from the acquirer to the merchant server. Therefore the merchant must develop his own mechanisms to process different financial operations and verify that payments match orders.

\section{InTEgRATION OF InTERnet PAyMENT System}

To get into the depth of the integration of electronic payment system, we propose to start by studding the most important brakes of integration in order to propose a new model easy to integrate into the e-commerce websites.

\section{A. Integration Brakes}

In November 2001, Electronic Payment Systems Observatory ePSO organised a workshop on payment [13], presenting a complex picture of the integration of a payment system and a basket full of problems; Payment system integration in the transaction process is difficult, because payment systems are like "black boxes" encapsulated in the communication on open networks. Each system has its own procedural logic, contractual and legal basis, and is maintained and controlled from outside.

As we presented in section II, electronic payment systems are never only about payments. They do always go together with additional ingredients: technical security measures, legal regulations and potential law enforcement, contractual regulations of liabilities and insurance against risks, collection of digital proofs, and guaranty of payment. But security of the transaction remains the main concern with the electronic payment since money and merchandise are transferred without direct contact between parties involved in the transaction and in order to accept payments and process transactions through his website securely, e-merchant can delegate the payment system to a payment service provider that processes electronic payment on behalf of him and connects to multiple acquiring banks and card networks, thereby making the merchant less dependent of financial institutions. Therefore, a merchant must add a link to the shopping cart or catalogue to transfer the customer to the payment provider for card processing. Then, the payment service provider verifies the credit card purchase, collects the payments and deducts the commissions.

The question now is until not all payment means are not online yet, so what are the most important brakes of payment system integration into B2C e-commerce websites?

\section{A.1 Complexity}

One of the most important brakes of integration is the complexity of the integration in the online shop, in fact, when designing a payment system, the merchant must take into consideration many factors because electronic payment systems are more than the payment function, they are also about payments technical security measures, authentication mechanisms, legal regulations and potential law enforcement, contractual regulations of liabilities and insurance against risks.

As it is presented in figure 2, payment instrument issuers have two alternatives in order to be used on internet; The first one consists on the integration of the payment system directly on different merchant websites which may take much time because every electronic market is different from the other. The second alternative, and as merchants generally delegate their payment systems to payment service provider, the payment method may be integrated in all PSPs' platforms in order to be displayed in different e-commerce websites which is not easy any more. And even if we suppose that the payment method may be displayed 


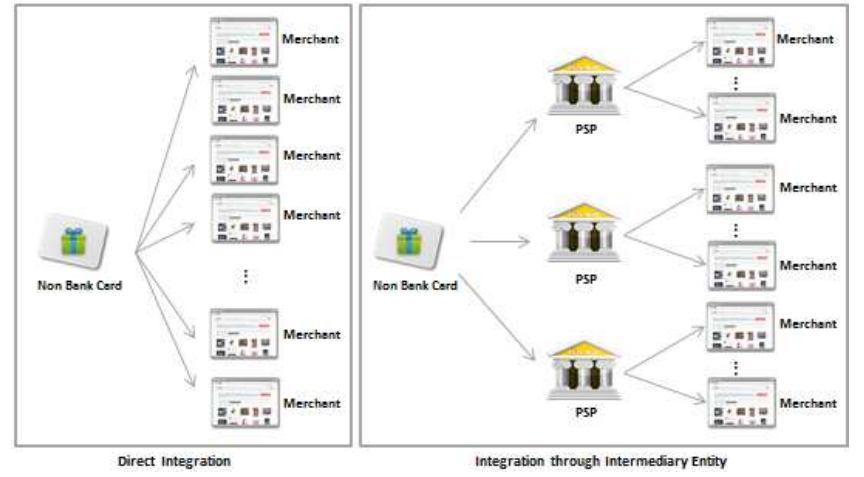

Figure 2. Payment System Integration Ways

easily on the merchant website, there are still other issues to resolve related to the back office process and the payment matching and orchestration.

\section{A. 2 Cost}

In order to more understand payment system integration limits and to estimate the integration cost, we have made a survey questionnaire which was answered by some selected emerchants and nonbank card issuers. The survey produced valuable results that are summarized in table 2 .

\begin{tabular}{|l|c|c|}
\cline { 2 - 3 } \multicolumn{1}{c|}{} & Time & Cost \\
\hline Small online Shop & 10 man days & $300-400 €$ per day \\
\hline Middle online Shop & $20-30$ man days & $550 €$ per day \\
\hline Big online Shop & $40-60$ man days & $550 €$ per day \\
\hline
\end{tabular}

Table 2. Time/Cost of Technical Integration

As expected, the integration of a payment system for a B2C e-commerce market, takes much time which makes it very expensive. The merchant must also pay commissions to financial institutions and installation fees as a percentage of each transaction or a fixed per transaction amount which may increase the transaction cost. For example, if the merchant decides to integrate directly the payment terminal into the online website, then it will cost $150-700 €$ to open a bank merchant account plus yearly account maintenance fees as it is presented in table 3 below.

\begin{tabular}{|c|l|c|c|c|}
\cline { 3 - 5 } \multicolumn{2}{c|}{} & Service Fees & Subscription & $\begin{array}{c}\text { Commission } \\
\text { per Transaction }\end{array}$ \\
\hline \multirow{4}{*}{ Banks } & Sogenactif & $153 €$ & - & - \\
\cline { 2 - 5 } & CyberMut & $150 €$ & $15 € /$ Month & $0,8 \%+0,15 €$ \\
\cline { 2 - 5 } & CyberPlus & $200 €$ & $23 € /$ Month & $1 \%+0,17 €$ \\
\cline { 2 - 5 } & E-Transaction & $242 €$ & $16 € /$ Month & - \\
\hline \multirow{4}{*}{ PSPs } & Paybox & $390 €$ & $21,71 €$ & $0,061 €$ \\
\cline { 2 - 5 } & Ogone & $300 €$ & $85 € /$ Month & $0,14 €$ \\
\cline { 2 - 5 } & Fia-Net & $700 €$ & $500 € /$ Year & $0,25-0,70 \%$ \\
\cline { 2 - 5 } & EPay & $390 €$ & - & $0,89 €$ \\
\hline
\end{tabular}

Table 3. Online Transaction Commissions (duty-free)

The online processing service providers charge also fees for each transaction as will the financial institution that manages the merchant account. But they deduct a higher commission than the banks (see table 3) because they offer more payment services and risk management.

The e-commerce website needs also to purchase customized software which can interact with the online processing service provider server and allow the merchant to know within seconds whether the charge has been approved.

\section{B. New Internet Payment Model}

In this section we will interest to merchants who have installed an online bank card payment and want to install a new payment mean (gift card, loyalty card,...). In this case, merchant must do the same integration instructions and manage two different payment channels (bank and nonbank one) which is complicated. We propose a new payment system that enables new payment instrument to be integrated on any website without technical integration on the merchant side. This new payment system allows aggregation of many payment means and transforms several payment instrument into one bank card payment accepted by any online market.

The new payment system that we will describe in this section has the major innovation to not need a particular integration from the merchant; the merchant must only process online bank card payment (credit card, debit card,...). And as bank cards are the primary means of payment for goods and services purchased online, so our proposed model can be widely used thanks to the success of online bank card payment system.

The mean idea of this new payment system is to convert any payment to a credit card payment using a Dynamic Virtual Card (DVC) which is a bank card bound to a single transaction or with a single merchant and a maximum transaction amount and generated dynamically at the moment of payment [14]. This new scheme of transaction is very convenient for the merchant because new payments can be displayed, processed and matched without changing the infrastructure currently in place.

\section{B.1 New Transaction Process}

In order to handle different integration limitations, we propose an intermediation payment service that processes and controls all transactions on behalf of the merchant. It is an open payment gateway without any direct integration in online-shops. It enables cardholders to buy from any website using any payment mean. In this new payment model, the payment service provider processes the client payment and then if the payment card issuer approves the payment, the merchant is paid using the dynamic virtual card system.

This new payment system acts as a Web Proxy Server between the client computer and the merchant server. In computer networks, a proxy server is a server that acts as an intermediary for requests from clients seeking resources from other servers [15]. It evaluates requests according to its filtering rules. For example, it may filter traffic by IP address or protocol. If the request is validated by the filter, the proxy provides the resource by connecting to the relevant server and requesting the service on behalf of the client.

As figure 3 shows, a proxy server works as intermediate server to send the requests (http,ssl,ftp,...) to other servers on 


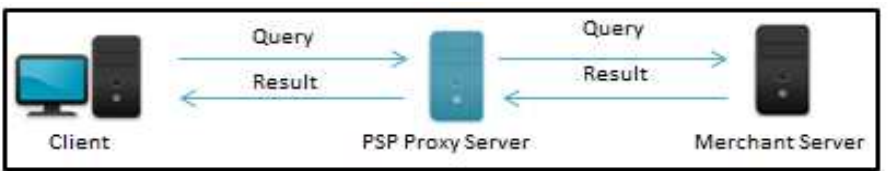

Figure 3. Web Proxy Server

Internet on behalf of other computers. It is like a middle man, works between the user's computer and the server from where user tries to download web pages or other resources. As an example, a user can send a http request from the computer to proxy server, then the proxy server will communicate with the web server (computer will not talk to web server directly) and then return the web page information back to the user's computer. The proxy server can be a program installed on computer, proxy server set up on user home network or a public proxy server on Internet.

Based on this new definition of the e-payment model, we can generate a wide range of scenarios. In this paper we are interested in studding a simple scenario that describes a payment with a single instrument. The new transaction model presented in the Figure 4 below involves the following exchanges between the customer, the merchant, the payment service provider, the nonbank card issuer, the DVC issuer, the acquirer.

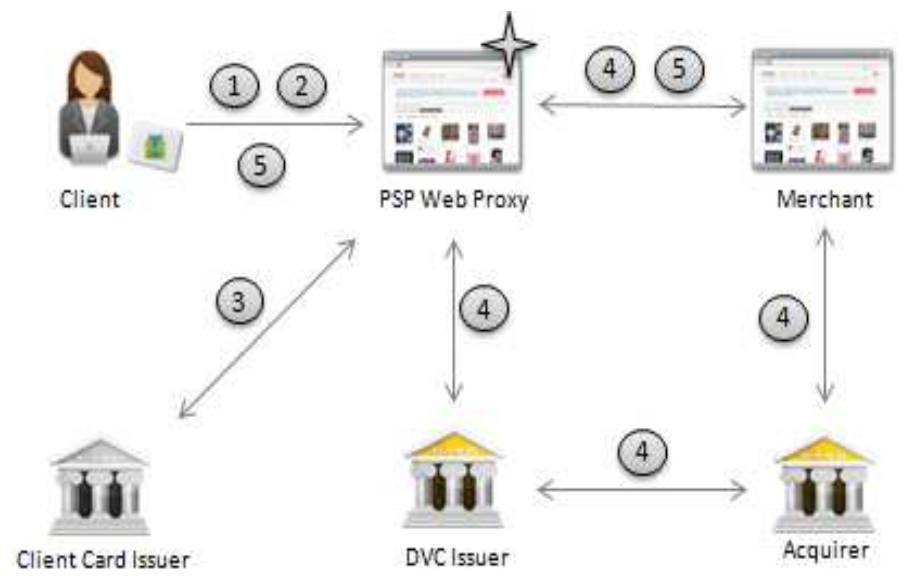

Figure 4. New Transaction Flow

\section{Step 1 : Merchant Selection and Command Validation}

The client selects the merchant where he wants to purchase from the PSP interface which displays all online shop that accept the payment card of the client. In this new payment model, the PSP acts as a web proxy server, he sends http requests to the merchant server on behalf of the client browser. After choosing a merchant shop, the consumer is redirected to a proxified merchant website which is a copy of the merchant shop. The PSP server sends the same client request to the merchant server, then returns the merchant response to the client browser and the client can browse the merchant website, fill his/her shopping cart and validate his/her command.

Step 2 : New Payment Mean Display

When the merchant displays the choice of accepted payment means, and as the PSP server acts as a proxy server and an intermediary between the merchant and the customer that implements filtering rules, so he can change the HTML code of the web page returned by the merchant server and add dynamically a new payment means in this page. Thus the payment card of the client is displayed in the online shop without direct integration on the merchant website. The client can then choose his/her non bank payment card as a payment mean and be redirected to the payment page.

In the meantime, a waiting page is displayed to the client as it is presented in figure 5 and the PSP adds a javascript that simulates the choice of the bank card payment and sends a bank card payment request to the merchant server that returns the bank card payment page. The Javascript code which is embedded directly in the merchant web site and interpreted when the page is loaded [16], fills the payment with a dynamic virtual card DVC of $1 €$ and validates the payment.

When the proxy server validates the bank card payment form, a http request is performed to be sent to the merchant (or the merchant PSP) server. Then it is intercepted and stored in the database in order to use it later (in step 4) so it is not transmitted to the payment server of the merchant.

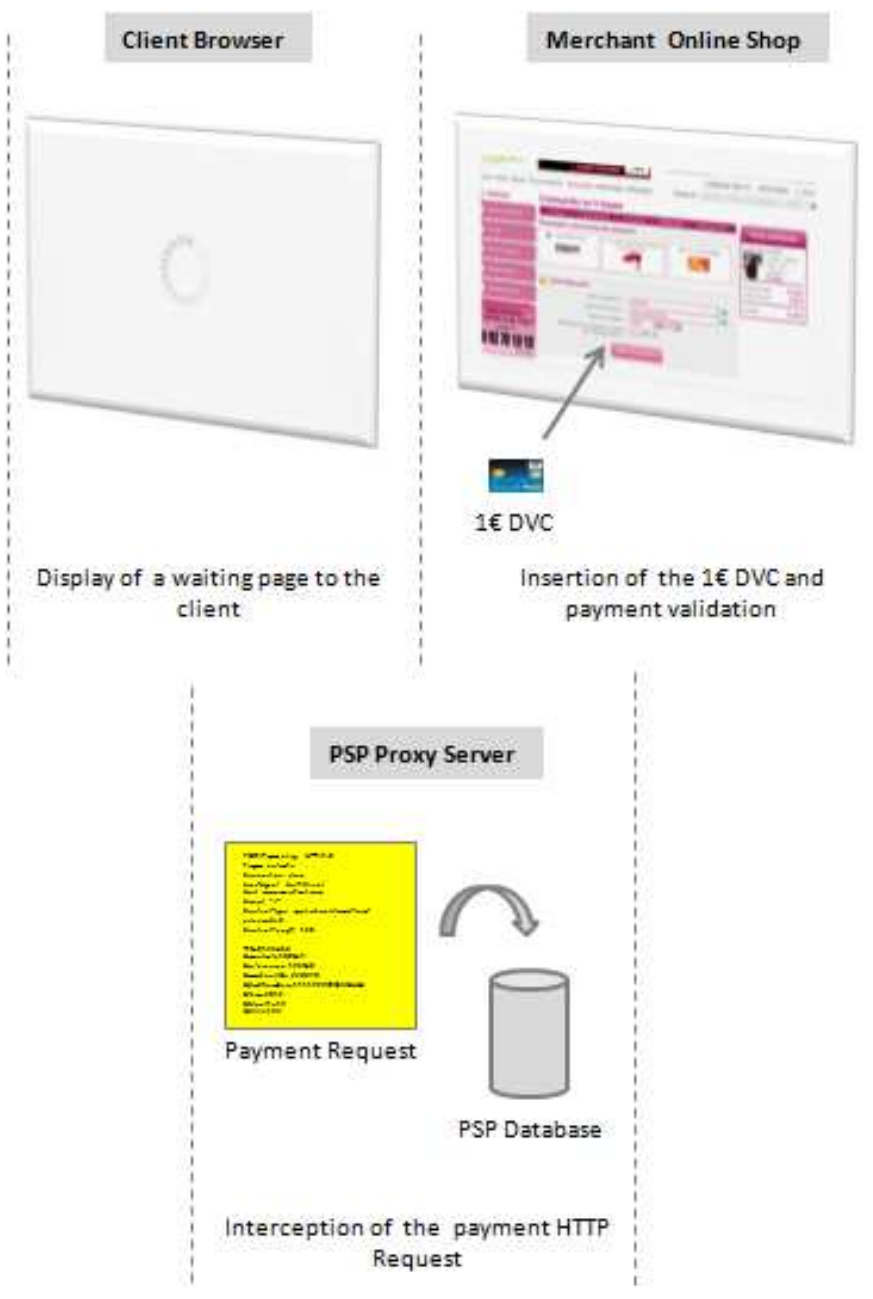

Figure 5. Conversion of Non Bank Card Payment to Bank Card Payment 


\section{Step 3 : Non Bank Card Payment}

The client is redirected to the payment page and the PSP processes the payment card credentials and sends an authorization request to the payment card issuer.

\section{Step 4 : Non Bank Card Payment Conversion}

If the authorization response is OK and the client card issuer returns an authorization number to the PSP, so a Dynamic Virtual Card may be generated in order to pay the merchant. Then the PSP proxy server processes the bank card payment form stored in database in step 2 of transaction and replaces the $1 € D V C$ by the generated one and submits the payment request. As web applications today are session-oriented [17] and the PSP Web Proxy server has established a web session with the merchant server and obtained a session ID which is used to interact with the merchant web application server over the stateless HTTP protocol, the PSP can send the bank card payment request on behalf of the client because all http cookies were intercepted by the PSP web server. HTTP Cookies, also known as Web cookies, are small parcels of text sent by a server to a web browser and then sent back unchanged by the browser if it accesses that server again [18]. They are originally designed to carry information between servers and browsers, and they were used in this payment scenario to match the the payment request to the client shopping cart.

Since the merchant have installed a bank card payment system, so the DVC will be processed normally without any modification of the merchant payment gateway. The merchant requests for a payment authorization from the DVC issuer. This request is handled through the merchant acquirer who transfers all payment information to the DVC issuer and waits for the response. When the acquirer receives the response of payment authorization, he sends it to the merchant who updates the state of the command.

\section{Step 5 : Payment Confirmation}

If the payment result is $\mathrm{OK}$, the merchant sends a payment confirmation to the PSP proxy server, who forwards it to the customer. If the payment is refused, the client receives an error page and s/he may choose another payment mean.

\section{B.2 Financial Flow}

In this new payment system model, the PSP acts as an Electronic Money Issuer (EMI) which is a financial institution that issues means of payment in the form of e money and is duly authorised to do so [19]. Electronic money is the monetary value stored electronically on receipt of funds and which is used for making payment transactions. The payment service provider proposes an open platform where issuers and merchants can create e-money accounts to receive payment and to add bank accounts to fund e-money account or wire money to bank accounts.

In order to be integrated in this open payment gateway, the non bank payment card issuer creates a business account and fund it with a bank account. The issuer account will be used to generate the DVC in order to pay the merchant. in the other hand, to propose a new payment means the merchant does not have to open any account to receive payment because he already opened a bank account to perform bank card payments. Unlike other financial institutions (such as payment institution), an
EMI can create anonymous account under some conditions [20], which can be considered as a major advantage to encourage issuers to create accounts and to join the open payment platform. During a simple electronic payment transaction, the generated Dynamic Virtual Card is related to the issuer account and when the DVC is charged, money is wired from the e-money issuer account to the merchant bank account account.

A more complicated payment scenario is presented in figure 6 , This case deals with the payment means aggregation when the transaction amount is more than the non bank card balance and the client has to perform a complementary payment with a bank card.

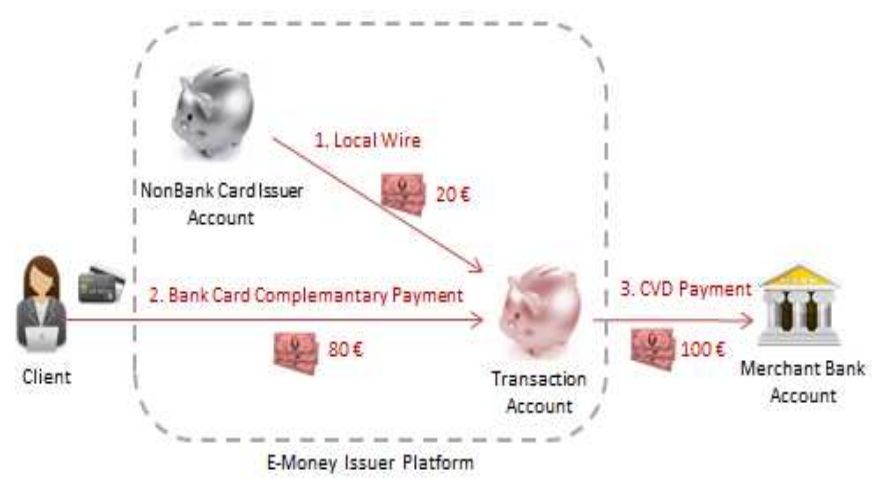

Figure 6. Financial Flow

To more understand financial flow in this payment scenario, let's assume the following scenario, the client has a gift card with $20 €$ and wants to pay his shopping cart (100€). If the authorization response of the non bank payment card issuer is $\mathrm{OK}$, the payment service provider (e-money issuer) transfers $20 €$ from the gift card issuer account to the transaction account which is a temporarily account created for the duration of the transaction and can only charged by the receiver (the merchant). And after the reception of the authorization request from the client bank card issuer (performed during the the complementary payment), The transaction account is then funded by $80 €$. Finally, a DVC of $100 €$ is generated from this account and send to the merchant bank card payment system in order to be processed. When the DVC is charged, money is wired from the transaction account to the bank account of the merchant.

\section{New Payment System Integration}

As we presented in previous sections, there are many factors that must be taken into consideration while designing a new payment system on internet that consist especially on the diversity of payment means, payment system requirements and typologies of existing payment systems. In this section, we will analyse how our proposed model resolves those issues and handles the two principal brakes of the integration which are complexity and cost.

In the new payment model, the merchant that has integrated bank payment card system, does not have to worry about how to display new payment methods in his online shop and to accept a new payment instrument. The PSP proxy server adds dynamically the new payment mean without any modification of the 
merchant website so the technical integration is reduced to 0 days man. In this way, several payment means can be added dynamically in an online shop without any technical integration on the merchant website.

Furthermore, the merchant does not have to process new payments, the PSP proposes the appropriate payment page to the cardholder and processes nonbank card payment authorisation then transforms them to a bank card payments, then the merchant is paid with a dynamic virtual card and since he has already integrated a bank card payment system, he has nothing to do. In addition, merchant does not have to match new payments and orders and to process two payment channels, the PSP performs the payment orchestration and processes different financial operation related to the transaction (charge, authorization request, refund, etc). New payments are transformed into bank card payment so they are matched like other bank card payments received by the merchant.

In the non bank payment card issuer side, it is easier to be integrated in only one PSP in order to be accepted and displayed in many e-commerce websites rather than be integrated in many PSPs. And in the the merchant side, it is easier to integrate one payment platform that accepts all non bank payment cards and processes payment orchestration.

This leads us to the conclusion that the new payment model handles the two principal brakes of payment system integration; it is simple and easy to integrate for the merchant and the issuer and then it is less expensive because the integration do not take much time. Furthermore, the new payment system enables a simple integration into B2C e-commerce while guaranteeing different payment system assessments. All transaction steps (the non bank card payment, the DVC generation and the bank card payment) are handled by the PSP server, using SSL protocol. The new payment model guaranties authentication, confidentiality, integrity and different payment system requirements and especially the economic requirements because it reduces the transaction cost and increases the ROI.

\section{Conclusion And Perspectives}

The most fundamental aspect of all commercial transaction processes on Internet is the exchange of monetary value. Contrarily to the simple case of a face to face purchase of physical goods and payment with cash, the virtual value exchange over Internet is complicated and is subject of various issues. In the $\mathrm{B} 2 \mathrm{C}$ commerce the electronic payment system integration is central for the merchant. Usually the seller presents a catalogue of products and services and chooses a payment system. But this choice depends on various factors that complicate payment system integration: Which payment means will be proposed? Will the payment system be hosted by the merchant server or it will be outsourced? How to guaranty payment system requirements compliance? etc. In fact, the "real integration problem" depends on the concept of "integration"; The strictest concept of integration would claim that the more steps of an online transaction process are done on the Internet, the higher the level of integration.

The evolution of B2C commerce has included the appearance of new payment means, which are not yet as widespread as bank payment cards. Among the reasons of this problem is the com- plexity and the cost of the integration of a new payment mean.

In this paper we presented a new payment model which is easy to integrate into e-commerce online shops while guaranteeing different payment system requirements. The proposed payment system acts as a web proxy server between the client browser and the merchant server. It is an open payment platform that enables non bank card payments in several e-shops without any technical integration. In further works we will interest to improve this payment model.

\section{ACKNOWLEDGMENT}

The authors wish to thank Nicolas Benady for his valuable suggestions for this paper and Limonetik and its financial support.

\section{REFERENCES}

[1] Lelieveldt Consultancy "Research study on the integration of e-payments into the online transaction process". Amsterdam, December 12, 2001.

[2] A. Patel, W. Qi, C Wills, "A review and future research directions of secure and trustworthy mobile agent-based e-marketplace systems", Information Management and Computer Security , 18(3) Emerald, pp. 144 - 161. ISSN 0968-5227 (2010).

[3] Regina Connolly, and Frank Bannister, "Consumer Trust in Electronic Commerce: Social \& Technical Antecedents" World Academy of Science, Engineering and Technology 342007

[4] Lee, T.O., Yip, Y.L., Tsang, C.M., and Ng, K.W. 2001. An Agent-based Micropayment System for E-Commerce. in J. Liu and Y. Ye, ed. E-Commerce Agents. Lecture Notes in Artificial Intelligence vol. 2033 (Springer-Verlage Berlin Heidelberg). pp. 247-263.

[5] Laudon, K. and Traver, C., "E-Commerce: Business, Technology, Society". Addison Wesley, Boston, MA., 2002.

[6] U.Shankar, M.Walker, "A Survey of Security in Online Credit Card Payments" UC Berkeley Class Notes, May 2001.

[7] Flore Fauconnier, "3DSecure : le bilan" Journal du Net/ Rudy Salin 17 March 2010. http : // www . journaldunet . com / ebusiness / commerce / bilan-3dsecure / multiples-difficultes . shtml

[8] Hsiao-Cheng Yu, Kuo-Hua Hsi, Pei-Jen Kuo. "Electronic payment systems: an analysis and comparison of types". Technology in Society 24 (2002) 331-347

[9] B. Clifford Neuman, "Security, payment, and privacy for network commerce". IEEE Journal on Selected Areas in Communications, 13(8):15231531. October 1995.

[10] Tsiakis, T., Stheohanidews, G.: "The concept of security and trust in electronic payments" Computer \& Security 24(1), 10-15 (2005).

[11] Michel Benaroch, Ajit Appari, "Pricing e-service quality risk in financial services" Electronic Commerce Research and Applications, November 2010.

[12] Refka Abdellaoui, Marc Pasquet "'Secure Communication For Internet Payment In Heterogeneous Networks" International IEEE Conference, Advanced Information Networking and Applications (AINA),Perth, Australia, 20-23 April 2010.

[13] Knud Böhle, 'Integration of Internet Payment Systems : What's the Problem?", ePSO Newsletter - No. 11, Spain, December 2001.

[14] Ian Molloy , Jiangtao Li , and Ninghui Li, ”Dynamic Virtual Credit Card Numbers", Financial Cryptography and Data Security Feb. 2007.

[15] A Pathak, J Cervantes, H Tjhen, L Luna, "Web Proxy Server" http : // www . calstatela . edu/

[16] ECMA International. "ECMAScript Language Specification". ECMA262, 3rd edition, December 1999. http : // www . ecma-international . org/ publications / files / ECMA-ST / Ecma-262 . pdf

[17] Henry Song, Hao-hua Chu, Nayeem Islam, Shoji Kurakake, and Masaji Katagiri, "Browser State Repository Service" In Friedemann Mattern, Mahmoud Naghshineh, editors, Pervasive Computing, First International Conference, Pervasive 2002, Zürich, Switzerland, August 26-28, 2002, Proceedings. Volume 2414 of Lecture Notes in Computer Science, Springer, 2002.

[18] HTTP Cookie, http : // en . wikipedia . org / wiki / HTTP_cookie

[19] Directive 2000/46/EC dated 18th September $2000 \mathrm{http}$ : //eur-lex .europa. eu / LexUriServ / LexUriServ . do ? uri = CELEX : 32000L0046 : EN : NOT

[20] John P. Watson, Andres E. Larriera, Martin Kuhnemund, "Evaluation of The E-Money Directive (2000/46/EC)" submitted to the DG Internal Market, The European Commission. 